\title{
COMPARISON OF EARLY APPENDECTOMY VERSUS CONSERVATIVE MANAGEMENT FOR APPENDICULAR LUMP AT TERTIARY CARE HOSPITAL.
}

1. MBBS, MS

Assistant Professor Surgical Unit 3 PUMHSW Nawabsha.

2. MBBS, FCPS

Associate Professor Surgical Unit 3 PUMHSW Nawabshah.

3. MBBS, MS

Assistant Professor Surgery

PUMHSW Nawabshah.

4. MBBS, MS

Senior Registrar Surgical Unit 3 PUMHS Nawabshah.

5. MBBS, FCPS

Professor and Head Surgery PUMHSW Nawabshah

6. MBBS, MS

Senior Registrar Surgical Unit 2 PUMHSW Nawabshsh.

Correspondence Address: Dr. Altaf Hussain Ghumro Department of Surgical Unit 3 PUMHS Nawabshah.

altafkhadim@yahoo.com

Article received on:

17/02/2020

Accepted for publication: 25/05/2020
Zulfiqar Ali Imtiaz Memon', Mashooque Ali Khowaja², Inayat Ali Zardari³, Altaf Hussain Ghumro4, Farkhanda Jabeen Dahri ${ }^{5}$, Imtiaz Ali Soomro ${ }^{6}$

ABSTRACT... Objectives: The purpose is to compare two options of management of appendicular lump in order to sort out the better one for the benefit and betterment of populace. Study Design: Cross Sectional study. Setting: Peoples Medical College Hospital Nawabshah. Period: 2016 August to August 2018. Material \& Methods: Total 50 patients of appendicular lump were included in this research. All patients were divided into 2 groups. Group 1 included those patients undergoing emergency appendectomy. They were admitted, optimized and the required treatment was initiated. Results: Of total 50, 30(60\%) were male and $20(40 \%)$ were females. Age was between 14 to 51 years. All patients presented with different clinical presentations. Pain in RIF was in $42(84 \%)$ patients whereas $47(94 \%)$ patients presented with lump in RIF. 20(40\%) patients were operated for appendectomy in emergency and $5(10 \%)$ patients for right hemi-colectomy. Histopathological diagnosis was inflammation in $24(48 \%)$ patients and $1(2 \%)$ resulted in cecal tumor. Infected wound was found in $15(30 \%)$ patients, hematoma in $3(6 \%)$, wound dehiscence in $1(2 \%)$ and also cecal fistula in 1 (2\%). Conclusion: Conservative treatment is better option to treat appendicular lump with least negative results.

Key words: $\quad$ Appendicular Lump, Appendectomy, Cecal Fistula, Right Hemicolectomy.

Article Citation: Memon ZAI, Khowaja MA, Zardari IA, Ghumro AH, Dahri FJ, Soomro IA. Comparison of early appendectomy versus conservative management for appendicular lump at Tertiary Care Hospital. Professional Med J 2020; 27(9):1818-1822. DOI: 10.29309/TPMJ/2020.27.09.3961

\section{INTRODUCTION}

Since the discovery of "acute appendicitis", its diagnosis has been perturbing the surgical faculty throughout the world. Clinical history, physical examination, biochemical and radiological investigations and also the introduction of multiple scoring systems are still quite insufficient to make accurate diagnosis in this context. ${ }^{1}$ It is still the most common surgical emergency recorded into emergency department of the hospitals around the world. Only $2-10 \%$ of patients present with appendicular lump. The lump is formed when the omentum walls off the inflamed appendix. When the perforated appendix is walled off, it usually presents as wide pathological spectrum ranging from inflammatory mass to localized abscess that later on can convert into localized peritonitis to generalized one..$^{2,3}$

It poses the risk to life of both genders with varying proportions. The lifetime risk for males and females is $8.6 \%$ and $6.7 \%$ respectively. Contradictory to this is the risk of appendectomy which is higher in females as compared to females. ${ }^{4}$ The risk for undergoing appendectomy for female is $12 \%$ and male $23 \%$. Of all cases of acute appendicitis, 3.8-5\% complains of developing enclosed inflammatory mass which, on certain criteria, is called phlegmon. ${ }^{5}$

The presentation of patients suffering from appendicular lump is the painful lump in RIF, anorexia, Nausea/vomiting and elevated temperature. An examination detects the palpable mass in RIF which is confirmed by Ultrasound of Abdomen and CT scans wherever it is necessary. In tertiary care hospitals in developing countries, ultrasound is commonly used as diagnostic tool for this disease assuring the diagnosis of $70 \%$ cases. ${ }^{6,7}$

Evidence is found that the frequency and 
prevalence of enclosed inflammation is continuously increasing due to the treatment of acute appendicitis on antibiotics as first line therapy. Conservative treatment shows $73 \%$ success rate but there is risk of recurrence among $50 \%$ patients which is the etiological factor for developing complicated appendicitis. Conservative management was unveiled by Ochsner in 1901.8 This regimen keeps the patients NPO, antibiotics use and bed rest and monitoring of the clinical features for few days. $80 \%$ of patients respond on this therapy and they are called on after 8-12 weeks for interval appendectomy. ${ }^{9}$

Till today, there are no standardized management guidelines for complicated acute appendicitis. A lot of difference has been found among the consultants and registrars regarding the treatment of acute appendicitis. Recent study published has indicated that conservative treatment has caused fewer complications as compared to early appendectomy. ${ }^{10}$

The rationale of our study is to compare two management options for appendicular lump in order to find the better option for the sake of benefit of the patients and to decrease morbidity and mortality of the patients.

\section{MATERIAL \& METHODS}

This research regarding the management of appendicular lump was conducted at surgical department of $\mathrm{PMCH}$ Nawabshah for the period of 2 years from 2016 August to August 2018. This study was conducted on 50 patients with diagnosis of appnedicuar lump. Total 250 patients were admitted with diagnosis of acute appendicitis. History and physical examination was done. In history, age, sex, main symptoms along with duration, heart rate and the temperature at the time of admission was noted. Examination of abdomen shows palpable lump in RIF. Ultrasound of abdomen and CT scan in selected patients were gotten and found appendicular lump among 50 patients that were selected for the study. Two groups were formed. Group 1 included 25 (50\%) and Group 2 having 25 (50\%) patients. Routine investigations were done and leucocytosis was found in most of the patients. Group 1 was treated with early appendectomy and Group 2 was treated conservatively. Results were made according to Ochsner regime, complications of surgery and duration of hospital stay.

\section{RESULTS}

Total 50 patients included in this study. Of all, $30(60 \%)$ were male and $20(40 \%)$ were females. Age was between 14 to 51 years. All patients presented with different clinical presentations. Pain in RIF was found among $42(84 \%)$ patients whereas $47(94 \%)$ came with lump in RIF. Nausea and vomiting was the symptom among $27(54 \%)$, fever in $35(70 \%)$, diarrhea in $7(14 \%)$, constipation in $8(16 \%)$, tenderness in RIF in $42(84 \%)$, heart rate from 92 to110 beats per minute in 33(66\%) and increased WBCs in 48(96\%) patients.

\begin{tabular}{|c|l|c|c|}
\hline $\begin{array}{c}\text { Sr. } \\
\text { No }\end{array}$ & Clinical Features & $\begin{array}{c}\text { No of } \\
\text { Patients }\end{array}$ & Percentage \\
\hline 1 & Pain in RIF & 42 & $84 \%$ \\
\hline 2 & Lump in RIF & 47 & $94 \%$ \\
\hline 3 & Nausea and vomiting & 27 & $54 \%$ \\
\hline 4 & Fever & 35 & $70 \%$ \\
\hline 5 & Diarrhea & 7 & $14 \%$ \\
\hline 6. & Constipation & 8 & $16 \%$ \\
\hline 7. & Tenderness in RIF & 42 & $84 \%$ \\
\hline 8 & Increased HR & 33 & $66 \%$ \\
\hline 9 & Leucocytosis & 48 & $96 \%$ \\
\hline & & \\
\hline
\end{tabular}

Emergency surgery was performed in Group 1 patients. Appendectomy was done in 20(40\%) patients and $5(10 \%)$ patients were operated for right hemi-colectomy due to severe inflammation, adhesions and suspicious cecal tumor. Histopathological diagnosis was inflammation in $24(48 \%)$ patients and $1(2 \%)$ resulted in cecal tumor.

Group 2 was treated conservatively. 20 (40\%) patients got relief with 3 to 5 days and were discharged home and called for follow up after 4 to 6 weeks. 5(10\%) patients symptoms subsided after a week. 20(40\%) were operated for abscess under ultrasound/ CT guided and also open surgery. Remaining did not return as there is possibility of non recurrence of the disease. 
The patients of Group 1 developed complications due to emergency surgery performed. Infected wound was found in $15(30 \%)$ patients, hematoma in $3(6 \%)$, wound dehiscence in $1(2 \%)$ and also cecal fistula in 1 (2\%).

\begin{tabular}{|c|l|c|c|}
\hline $\begin{array}{c}\text { S. } \\
\text { No }\end{array}$ & \multicolumn{1}{|c|}{ Complications } & Patients & Ratio \\
\hline 1 & Wound infection & 15 & $30 \%$ \\
\hline 2 & Subcutaneous hematoma & 3 & $6 \%$ \\
\hline 3 & Wound dehiscence & 1 & $2 \%$ \\
\hline 4 & Cecal fistula & 1 & $2 \%$ \\
\hline 5 & Total & 20 & $40 \%$ \\
\hline
\end{tabular}

Group 2 patients developed complications but with least ratio. Only 20(40\%) patients developed abscesses and 3(6\%) patients came with recurrence. No other complication was diagnosed in this group.

\section{DISCUSSION}

Appendicular lump is the condition with different presentation and having multiple complications. It can damage the appendicular wall leading to perforation forming the mass in RIF. Commonly three ways are to be considered by Surgeon to deal with this condition. Either emergency/ interval surgery or conservative methodology is applied by them. Throughout the world, the lump is treated conservatively by particular regimen called Ochsner. ${ }^{11}$

According to one study, 9 patients out of 23 were undergone US/CT guided percutaneous drainage but in our study, it was done in 20 patients out of 25 totals. In same study, 22 out of 23 responded well on conservative treatment. In our study, same was also found. All patients in our study treated conservatively responded but with some variations. Among 5 patients the response was slow and they got relief from symptoms after 5 days. ${ }^{12}$

The main drawback of conservative treatment is the missing pathologies or hidden other visceral diseases like cecal tumors or Crohn's Disease. So it is essential that these suspicious cases should investigated properly by colonoscopy, barium enema and CT scan. These investigations are important in patients with age of 40s. In a study, one case of Crohn's disease was found but in our study no any such findings were identified. ${ }^{13}$

Emergency surgery has also the complications with high frequency. These result from the edema of small and large intestine. This is the fact that in some appendicular lumps, colonic resections are done due to the inflammation and edema. In a study, operations of colonic resections in emergency surgery were more as compared to appendectomy. But in our study, the only $10 \%$ patients were operated for colonic resection and anastomosis. ${ }^{14}$

In one study, complication rate of conservative treatment is lower one to develop abscess or wound infection. But in our study, abscess developed was among $40 \%$ patients which were treated under radiological guidance with least complications. But in our study, the wound infection rate in emergency surgery was higher up to $30 \% .^{15}$

The study conducted by Brown et al showed the increased efficacy of conservative treatment but later on studies conducted by St Peter et al and Mentula et al showed the reduction in efficacy of conservative treatment in case of appendicular lump. But in our study, the conservative treatment is the better with least complications. The demerit of conservative treatment is that patients have psychological trauma of 6 weeks treatment and is continuously worried about the disease and in unaware of the complication to be developed in coming future. ${ }^{16}$

\section{CONCLUSION}

In our study, conservative treatment is considered to be the good one with least negative results and the management option to this is day care procedure to be done under ultrasound or CT guided so that patients may go back early to their home and job also.

\section{Copyright@ 25 May, 2020.}




\section{REFERENCES}

1. Snyder MJ, Guthrie M, Cagle S. Acute appendicitis: Efficient diagnosis and management. Am Fam Physician. 2018; 98(1):25-33.

2. Tannoury J, Abboud B. Treatment options of inflammatory appendiceal masses in adults. World $\mathrm{J}$ Gastroenterol. 2013; 19(25):3942-3950.

3. Salminen P, Paajanen H, Rautio T, Nordstrom P, Aarnio $\mathrm{M}$, Rantanen T, Tuominen R. et al. Antibiotic therapy vs appendectomy for treatment of uncomplicated acute appendicitis: The APPAC randomized clinical trial. JAMA. 2015; 313(23):2340-2348.

4. Flum DR. Clinical practice. Acute appendicitis appendectomy or the "antibiotics first" strategy. N Engl J Med. 2015; 372(20):1937-1943.

5. Sallinen V, AkI EA, You JJ, Agarwal A, Shoucair S, Vandvik $\mathrm{PO}$, Agoritsas T. et al. Meta-analysis of antibiotics versus appendicectomy for non-perforated acute appendicitis. Br J Surg. 2016; 103(6):656-667.

6. Ahmed I, Deakin D, Parsons SL. Appendix mass: Do we know how to treat it? Ann R Coll Surg Engl. 2005; 87(3):191-195.

7. Irfan M, Hogan AM, Gately R, Lowery AJ, Waldron R, Khan W, Barry K. Management of the acute appendix mass: A survey of surgical practice. Ir Med J. 2012; 105(9):303-305.

8. Simillis C, Symeonides P, Shorthouse AJ, Tekkis PP. A meta-analysis comparing conservative treatment versus acute appendectomy for complicated appendicitis (abscess or phlegmon) Surgery. 2010; 147(6):818-829.

9. Aranda-Narvaez JM, Gonzalez-Sanchez AJ, MarinCamero N, Montiel-Casado C, Lopez-Ruiz P, SanchezPerez B, Alvarez-Alcalde A. et al. Conservative approach versus urgent appendectomy in surgical management of acute appendicitis with abscess or phlegmon. Rev Esp Enferm Dig. 2010; 102(11):648652.
10. Mentula P, Sammalkorpi H, Leppaniemi A. Laparoscopic surgery or conservative treatment for appendiceal abscess in adults? A randomized controlled trial. Ann Surg. 2015; 262(2):237-242.

11. Di Saverio S, Birindelli A, Kelly MD, Catena F, Weber DG, Sartelli M, Sugrue M, De Moya M, et al. WSES Jerusalem guidelines for diagnosis and treatment of acute appendicitis. World J Emerg Surg. 2016; 11:34.

12. Salminen $P$, Paajanen $H$, Rautio $T$, Nordström $P$, Aarnio M, Rantanen T, Tuominen R, Hurme S, Virtanen J, Mecklin JP, et al. Antibiotic therapy vs appendectomy for treatment of uncomplicated acute appendicitis: The APPAC randomized clinical trial. JAMA. 2015; 313(23):2340-2348.

13. Svensson JF, Patkova B, Almström M, Naji H, Hall NJ, Eaton S, Pierro A, Wester T. Nonoperative treatment with antibioticsversus surgery for acute nonperforated appendicitis in children: A pilot randomized controlled trial. Ann Surg. 2015; 261(1):67-71.

14. Findlay JM, Kafsi JE, Hammer C, Gilmour J, Gillies RS, Maynard ND. Nonoperative management of appendicitis in adults: A systematic review and meta-analysis of randomized controlled trials. J Am Coll Surg. 2016; 223(6):814-824.e2.

15. Rollins KE, Varadhan KK, Neal KR, Lobo DN. Antibiotics versus appendicectomy for the treatment of uncomplicated acute appendicitis: An updated meta-analysis of randomised controlled trials. World J Surg. 2016; 40(10):2305-2318.

16. Podda M, Cillara N, Di Saverio S, Lai A, Feroci F, Luridiana G, Agresta F, Vettoretto N. ACOI (Italian Society of Hospital Surgeons) Study Group on Acute Appendicitis. Antibiotics-first strategy for uncomplicated acute appendicitis in adults is associated with increased rates of peritonitis at surgery. A systematic review with meta-analysis of randomized controlled trials comparing appendectomy and non-operative management with antibiotics. Surgeon. 2017; 15(5):303-314. 


\begin{tabular}{|c|c|c|c|}
\hline \multicolumn{4}{|c|}{ AUTHORSHIP AND CONTRIBUTION DECLARATION } \\
\hline Sr. \# & Author(s) Full Name & Contribution to the paper & Author(s) Signature \\
\hline 1 & Zulfiqar Ali Imtiaz Memon & Conception and design. & \\
\hline 2 & Mashooque Ali Khowaja & $\begin{array}{l}\text { Critical revision of the article } \\
\text { for important intellectual } \\
\text { content. }\end{array}$ & $\begin{array}{l}B_{x} \\
\text { don }\end{array}$ \\
\hline 3 & Inayat Ali Zardari & Data collection. & \\
\hline 4 & Altaf Hussain Ghumro & Drafting of the article. & \\
\hline 5 & Farkhanda Jabeen Dahri & Statistical expertise. & \\
\hline 6 & Imtiaz Ali Soomro & Proforma filling. & \\
\hline
\end{tabular}

